\title{
Speed Control of Induction Motor using PI and V/F Scalar Vector Controllers
}

\author{
Hanan Mikhael D. Habbi \\ Electrical engineering \\ department \\ University of Baghdad
}

\author{
Hussein Jalil Ajeel \\ Electrical engineering \\ department \\ University of Technology
}

\author{
Inaam Ibrahim Ali \\ Electrical engineering \\ department \\ University of Technology
}

\begin{abstract}
In this paper, Induction Motors (IM) are widely used in the industrial application due to a high power/weight ratio, high reliability and low cost. A Space Vector PWM (SVPWM) is utilized for PWM controlling scheme. The performance of both the speed and torque is promoted by a modified PI controller and $\mathrm{V} / \mathrm{F}$ scalar control. A scalar control is a simple method and it's operated to control the magnitude of the control quantities in constant speed application. V/F scalar control has been implemented and compared with the PI controller. The simulation results showed that Indirect Field oriented control (IFOC) induction motor drive employ decoupling of the stator current components which produces torque and flux. The complete mathematical model of the system is described and simulated in MATLAB/SIMULINK. The simulation results provides a smooth speed response and high performance under various dynamic operations.
\end{abstract}

\section{Keywords}

Induction motor, SVPWM, PI-Controller, V/F

$\begin{array}{ll}\text { ABBREVIATIONS } \\ i d s, i q s: \quad \text { the } \mathrm{d} \text { and } \mathrm{q} \text { axis components of the stator current } \\ i d r i q r: \quad \text { the } \mathrm{d} \text { and } \mathrm{q} \text { axis component of the rotor current } \\ \lambda d s, \lambda q s: \quad \text { the } \mathrm{d} \text { and q axis components of the stator fluxes } \\ \lambda d r, \lambda q r: \quad \text { the } \mathrm{d} \text { and } \mathrm{q} \text { axis components of the rotor fluxes } \\ v d s, v q s: & \text { the } \mathrm{d} \text { and } \mathrm{q} \text { axis components of the stator voltage. } \\ R \mathrm{~s}, \mathrm{R} r: & \text { the stator and rotor resistances. } \\ \omega \mathrm{r}: & \text { the rotor speed } \\ \mathrm{P}: & \text { the number of pole pairs } \\ \mathrm{N} & \text { the number of turns } \\ \lambda \mathrm{s} & \text { the magnetic flux-linkage in the stator } \\ \vec{\lambda}_{\mathrm{m}} & \quad \text { Air gap flux-linkage } \\ \mathrm{K} & \text { the constant of coil } \\ V_{r m s} & \text { The induced voltage in the stator, } \\ j \mathrm{~m}: & \text { the total motor and load inertia } \\ \mathrm{TL}, \mathrm{b}: & \text { the load torque and the friction Coefficient. } \\ L s: & \text { the stator inductances. } \\ L \mathrm{r}: & \text { the rotor inductances. } \\ \mathrm{Lm}: & \text { the mutual Inductance. }\end{array}$

\section{INTRODUCTION}

Three phase induction motors are the most widely used for industrial control and automation. They are often called the workhorse of the motion industries due to their robustness, reliability, less maintenance and of high durability [1]. Control Techniques of Induction Motor (IM) are Variable frequency control techniques of IM can be divided into two major types: scalar control, vector control methods. Scalar control or as it is called V/F control. The structure is very simple and it is normally used without speed feedback. However, this controller doesn't achieve a good accuracy in both speed and torque responses, mainly due to the fact that the stator flux and the torque are not directly controlled [3]. The main objective of this control method is, as in separately exited DC machines, to independently control the torque and flux; this is done by choosing a d-q rotating reference frame synchronously with the rotor flux space vector [4]. A voltage source inverter (VSI) should have a stiff voltage source at the input, that is, its Thevenin impedance should ideally be zero. Thus, a large capacitor can be connected at the input if the voltage source is not stiff. (VSI) consist of power bridge devices with three output legs, each consisting of two power switches and two freewheeling diodes, the inverter is supplied from DC voltage source (either battery or diode-based bridge rectifier) via LC or C filter [5]. The Space Vector Pulse Width Modulation (SVPWM) method is an advanced, computationintensive PWM method and possibly the best among all the PWM techniques for variable frequency drive application. It exhibits the feature of good dc-bus voltage utilization and Low total harmonic distortion (THD) compared to other PWM methods. SVPWM is more suitable for digital implementation and can increase the obtainable maximum output voltage with maximum line voltage approaching $70.7 \%$ of the DC link voltage in the linear modulation range [6]. SVPWM is adopted in this paper for PWM controlling scheme. In addition, a comparative study of the speed control of induction motor using V/F scalar vector and PI controllers is illustrated. The induction motor drive can be controlled to obtain better performance by many methods as scalar controller $(\mathrm{V} / \mathrm{F})$ and vector controller (Field oriented control and direct torque control) by using PI, intelligent controller, etc. In this section, a historical review of previous studies related to controlling the induction motor controller is introduced. Pabitra Kumar Behera et.al, 2014[7] presents a design and implementation of scalar control of induction motor. This method leads to be able to adjust the speed of the motor by control the frequency and amplitude of the stator voltage of induction motor, the ratio of $\mathrm{V} / \mathrm{F}$ is constant. It is also presents a comparative study of open loop and close loop $\mathrm{V} / \mathrm{F}$ control induction motor. The V/F control is based on advent of stator voltage derivatives. From experiment and results we shown that the closed loop V/F control gives better response and better result as compared to open loop V/F control of induction motor. Jay R. Patel, S.R. Vyas, 2014[1] proposed a Variable Voltage-Variable Frequency (V/F) base torque-speed control of three phase induction motor fed by a PWM Voltage Source Inverter will be simulated. The PWM method, which involves the modulation of conventional sinusoidal reference signal and a triangular carrier to produce pulse width modulated output signals, which are applied to 
Power Electronic Switches of a 2-Level Voltage Source Inverter, driving a Three Phase Induction Motor, shall be used. The performance analysis of three phase induction motor fed by PWM voltage source inverter in terms of phase current of inverter, rotor and stator current, speed, and electromagnetic torque developed of inverter is simulated. Simulation results illustrate the performance and effectiveness of constant V/F Induction Motor drive. The actual speed follows the reference speed and change in the speed from high to low and low to high makes change in the voltage and current profile accordingly. Devraj Jee, Nikhar Patel, 2013[8] presents the need of Speed Control in Induction Motors. V/F Control has proven to be the most versatile. The overall scheme of implementing V/F control has been presented. One of the basic requirements of this scheme is the PWM Inverter. In this, PWM Inverters have been modeled and their outputs fed to the Induction Motor drives. The uncontrolled transient and steady state response of the induction motor has been obtained and analyzed. A MATLAB code was developed to successfully implement open loop V/F Control on a PWMInverter fed 3-phase Induction Motor, and the Torque was found to be constant for various rotor speeds. It was observed that using a Closed-Loop scheme with a Proportional Controller gave a very superior way of controlling the speed of an Induction motor while maintaining a constant maximum torque. Riya Elizabeth Jose, Maheswaran K., 2015 [9] proposed the $\mathrm{V} / \mathrm{F}$ ratio that kept constant which in turn maintains the magnetizing flux constant so that the maximum torque remains unchanged.Z- Source inverter overcomes the shoot through short circuit problem of VSI. But ZSI has certain disadvantages which were overcome by switched boost inverter to modified pulse width modulation technique switched boost inverter (SBI) to drive a three phase induction motor. It is often required to control the output voltage of inverter for the constant voltage/frequency (V/F) control of an induction Motor. PWM (Pulse Width Modulation) based firing of inverter provides the best constant $\mathrm{V} / \mathrm{F}$ control of an induction Motor. Amongst the various PWM techniques, the sinusoidal PWM is good enough and most popular that provides Smooth changeover of V/F, four quadrant operation, harmonic elimination, in both closed and open loop applications. G. KOHLRUSZ, D. FODOR, 2011[10] there are two control methods are compared: scalar control and vector control, both control methods have advantages and disadvantages. Scalar control is a cheap, well-implementable method. Because of these advantages and its simplicity, many applications operate with this control technique in the industry. On the other hand, it is not satisfactory for the control of drives with dynamic behavior, since it gives slow response to transients. This is because the V/f Constant method controls the magnitude of voltages and frequency instead of controlling the phase and magnitude of currents. It is a low-performance, but stable control technique. The field oriented control method controls the currents so it operates with fast responses. This method satisfies the requirements of dynamic drives, where fast response is necessary. It is an excellent control method to handle transients. Its disadvantage is complexity, and the high price of the driver circuit. Nevertheless, it is a high-performance control technique. Both techniques are applicable over the nominal speed at the expense of torque

\section{MATHEMATICAL MODEL OF INDUCTION MOTOR}

The dynamic model of induction motor can be developed by writing differential equations for voltage and torque. For Dynamic analysis, poly phase windings are transformed into two phase windings (q-d) quantities [10]. The following equivalent circuit in Fig. (1) Is used to simulate a three-phase, $\mathrm{P}$-pole, symmetrical induction motor in the dq reference frame.

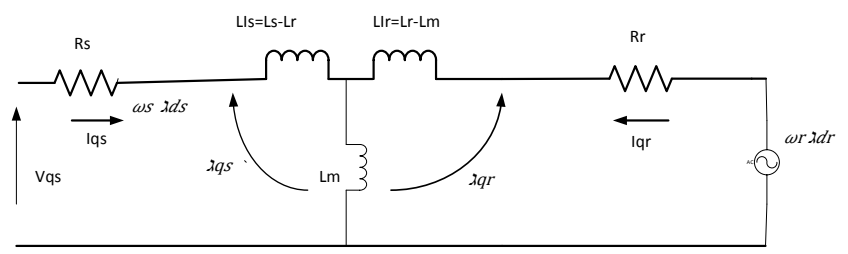

(a) q-circuit

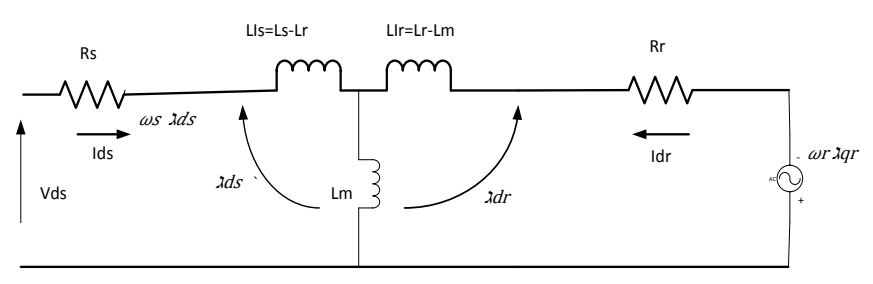

(b) d-circuit

Figure (1) induction motor equivalent circuit a) $q^{\mathrm{s}}$ circuit and $b) d^{s}$ circuit [11]

The dynamic machine model in stationary frame can be derived simply by substituting $\omega \mathrm{e}=0$. The corresponding stationary frame equations are given as

$$
\begin{aligned}
& v_{d s}=R_{s} i_{d s}+\frac{d}{d t} \lambda_{d s} \\
& v_{q s}=R_{s} i_{q s}+\frac{d}{d t} \lambda_{q s} \\
& 0=R_{r} i_{q r}+\frac{d}{d t} \lambda_{q r}-\omega_{r} \lambda_{d r} \\
& 0=R_{r} i_{d r}+\frac{d}{d t} \lambda_{d r}+\omega_{r} \lambda_{q r} \\
& \text { Where } v_{d r}=v_{q r}=0 .
\end{aligned}
$$

The fluxes are combined with the currents according to the following expressions

$$
\begin{aligned}
& \lambda_{d s}=L_{I s} i_{d s}+L_{M}\left(i_{d s}+i_{d r}\right)=L_{s} i_{d s}+L_{m} i_{d r} \ldots . .(5) \\
& \lambda_{q s}=L_{I s} i_{q s}+L_{M}\left(i_{q s}+i_{q r}\right)=L_{s} i_{d s}+L_{m} i_{q r} \ldots \text { (6) } \\
& \lambda_{d r}=L_{I r} i_{d r}+L_{M}\left(i_{d s}+i_{d r}\right)=L_{r} i_{d r}+L_{m} i_{d s} \ldots \text { (7) } \\
& \lambda_{q r}=L_{I r} i_{q r}+L_{M}\left(i_{q s}+i_{q r}\right)=L_{r} i_{q r}+L_{m} i_{q s} \ldots \text { (8) }
\end{aligned}
$$

The development of torque is by the interaction of air gap flux and rotor current [11] and [12]. Therefore, the torque can be generally expressed in the vector form as:

$$
\begin{aligned}
& \mathrm{T}_{\mathrm{e}}=\frac{3}{2}\left(\frac{\mathrm{P}}{2}\right) \vec{\lambda}_{\mathrm{m}} \times \overrightarrow{\mathrm{I}}_{\mathrm{r}} \ldots \ldots \ldots \ldots \ldots \ldots \ldots \ldots \ldots \ldots \ldots \ldots \\
& T_{e}-T_{L}=\left(\frac{2}{P}\right) \mathrm{J} \frac{d \omega_{r}}{d t} \ldots \ldots \ldots \ldots \ldots \ldots \\
& \mathrm{T}_{\mathrm{e}}=\frac{3}{2}\left(\frac{\mathrm{P}}{2}\right)\left(\lambda_{\mathrm{dm}} \mathrm{i}_{\mathrm{qs}}-\lambda_{\mathrm{qm}} \mathrm{i}_{\mathrm{ds}}\right)
\end{aligned}
$$




\section{SIMULATION OF INDUCTION MOTOR}

The inputs of a squirrel cage induction machine are the threephase voltages, their fundamental frequency, and the load torque. The outputs, on the other hand, are the three phase currents, the electrical torque, and the rotor speed, the induction machine model will have blocks transforming the three-phase voltages to the $\mathrm{d}-\mathrm{q}$ frame and the $\mathrm{d}$-q currents back to three-phase[12]. The block $\left(v_{a b c}\right.$ to $\left.v_{d q}\right)$ transforms three phase voltage $v_{a b c}$ into two phase stationary reference frame voltagesv $_{\mathrm{dq}}$. The simulation of the IM mathematical model is shown in Fig. (2), which consists of the main blocks: abc to dq block, D-axis circuit block, Q-axis circuit block, dq to abc current block, speed determination block and the torque determination block.

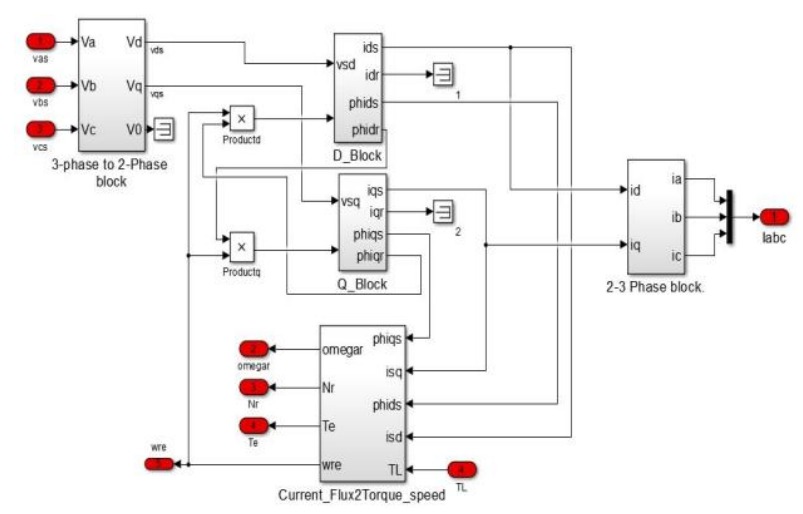

Figure (2) IM dynamic model Simulink circuit

To transfer the 2-axis stationary current frame ( $\left.\boldsymbol{i}_{q \boldsymbol{d}}^{\boldsymbol{s}}\right)$ to threephase stationary current frame $\left(\boldsymbol{i}_{\boldsymbol{a b c}}\right)$, using inverse transformation equation (12) [12].

$$
\left[\begin{array}{l}
i_{a} \\
i_{b} \\
i_{c}
\end{array}\right]=\left[\begin{array}{cc}
1 & 0 \\
\frac{-1}{2} & \frac{-\sqrt{3}}{2} \\
\frac{-1}{2} & \frac{\sqrt{3}}{2}
\end{array}\right]\left[\begin{array}{l}
i_{q}^{s} \\
i_{d}^{s}
\end{array}\right]
$$

\section{SPEED CONTROLLER}

In this section, two types of controllers were used, to enhance the FOC and scalar vector system for controlling the speed of IM, these controllers are:

1. V/F constant

2. Conventional PI controller (trial and error tuning)

\subsection{Scalar Control (V/F)}

$\mathrm{V} / \mathrm{F}$ is the most common speed control of an induction motor. The torque developed by the induction motor is directly proportional to the $\mathrm{V} / \mathrm{F}$ ratio. The voltage and frequency are tried to vary, keeping their ratio constant, then the torque produced by induction motor will remain constant for all the speed range [14]. In addition, V/F is the simplest controller. It assumes a constant relation between voltage and frequency and it is normally used without speed feedback. However, this controller doesn't achieve a good accuracy in both speed and torque responses, mainly due to the fact that the stator flux and the torque are not directly controlled [4]. The scalar control method is based on varying two parameters simultaneously. The speed can be varied by increasing or decreasing the supply frequency, but this results in change of impedances. The change of impedances eventuates the increase or decrease of current. If the current is small, the torque of motor decreases. If the frequency decreases or the voltage increases, the coils can be burned or saturation can occur in the iron of coils. To avoid these problems, it is necessary to vary the frequency and the voltage at the same time. In this way, the occurring disadvantages of changing frequency and voltage can be compensated. According to the equation of induced voltage the $\mathrm{V} / \mathrm{Hz}$ constant control gives constant flux in the stator (Eq. 13).

$$
V_{\text {rms }}=4.44 \text { K.N.גs. } f \text {. }
$$

The torque-speed equation of induction motors (Eq. 14) can be used to determine the voltage-torque

$$
T_{\text {air gap }}=\frac{3}{2 \omega_{m}} i^{2} \frac{R_{r}}{S} \ldots
$$

\subsubsection{Closed Loop V/F Control}

The basis of constant V/F speed control of induction motor is to apply a variable magnitude and variable frequency voltage to the motor (Fig. (3)). both the voltage source inverter and current source inverters are used in adjustable speed ac drives. The following block diagram shows the closed loop V/F control using a VSI.

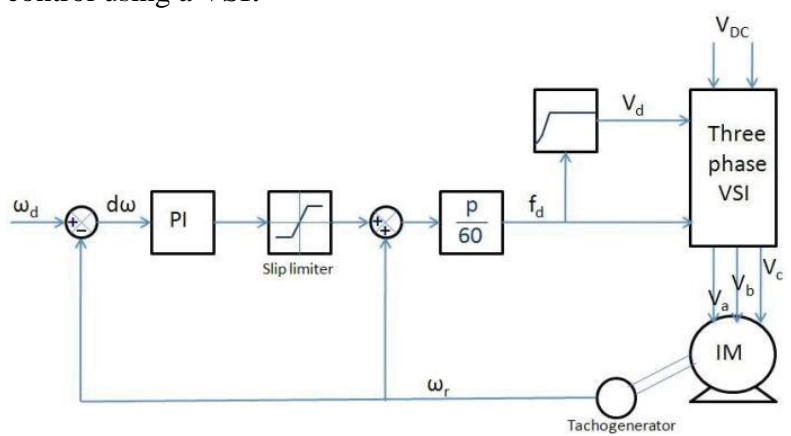

Fig. (3) Closed-loop V/Hz constant control

The closed-loop method offers a more precise solution to controlling the speed than the open-loop method. Furthermore, the closed-loop technique controls the torque, too. A major disadvantage of the open-loop control method is that this technique does not control the torque, so the desired torque is only accessible at the nominal operating point. If the load torque changes, the speed of the motor will change [7, 14].

\subsubsection{Open loop V/F control}

The open loop V/F control of an induction motor is the most common method of speed control because of its simplicity and these types of motors are widely used in industry. This type of motor control has some advantages are low cost, simplicity and immunity to errors of feedback signals .Traditionally, induction motors have been used with open loop $50 \mathrm{~Hz}$ power supplies for constant speed applications. For adjustable speed drive applications, frequency control is natural, however, voltage is required to be proportional to frequency so that the stator flux remains constant $\left(\lambda_{S}=\frac{v_{s}}{\omega e}\right)$ remains constant [7]. Block diagram of the open loop V/F control for an IM as shown in Fig. (4). 


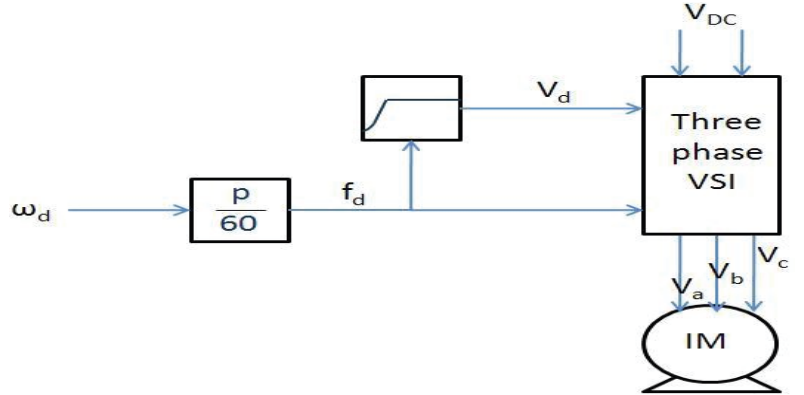

Fig (14) open loop constant V/F speed control [14]

Some problems encountered in the operation of this open loop drive, these problem are The speed of the motor cannot be controlled, because the rotor speed will be slightly less than the synchronous speed and that in this scheme the stator frequency and hence the synchronous speed is the only control variable. The effect of the above can make the stator currents exceed the rated current by a large amount. Then the slip speed cannot be maintained, due to the difference between the synchronous speed and the electrical rotor speed [7].

\subsection{Vector Controllers}

The field oriented control is one of the most prevalent control methods that are utilized to improve the dynamic performance of a three-phase induction because the FOC manner includes making the induction motor behave similar to a DC motor. The FOC is good and robust control in transient and it is based on mathematical abstraction .stator currents of the induction machine are separated into flux-and torque producing components by utilizing transformation to the $\mathrm{d}-\mathrm{q}$ coordinate system, whose direct axis (d) is aligned with the rotor flux space vector. It means that the q-axis component of the rotor flux space vector is always zero $[14,15]$.

$\lambda_{q r}=0, \lambda_{d r}=\lambda_{r}$

The speed error, with the help of a Conventional PI controller, is converted into a torque controlling current Component $\left(i_{q s} *\right)$, of the stator current. This current component is used to regulate the torque along with the slip speed. The control equation which The PI controller involves is given as

$$
i^{*}{ }_{q s}=k_{p} \Delta w_{r}+k_{i} \int \Delta w_{r} d t
$$

Similarly the flux producing current component $\left(i_{d s} *\right)$, is obtained from the stator flux linkage reference value and is given by the following

$$
\lambda_{r}=L_{m} i^{*} d s
$$

The rotor flux is directly proportional to current $i_{d s}$ in steady state

$I_{d s}=\frac{\lambda_{r}}{L_{m}}$

For the given flux level, the required torque

$T_{e}=\left(\frac{3}{2}\right) \frac{P}{2} \frac{L_{m}}{L_{r}} * \lambda_{r} * I_{q s}$

From the q current components and slip gain, the slip speed Relation is obtained as

$$
w_{s l}=\frac{L_{m} * R_{r}}{\lambda_{r} * L_{r}} i_{q s}
$$

Where $\tau_{r}$ is the rotor time constant, calculated by

$\tau_{r}=\frac{L_{r}}{R_{r}}$

In the indirect field oriented control $\theta f$ is achieved from calculated slip angle together with the feedback rotor speed based on motor parameters, is integrated to obtain the stator reference flux linkage space vector position $\theta \mathrm{e}$. Calculated by

$\Theta_{e}=\int w_{e} d t=\int\left(w_{s l}+w_{r}\right) d t$

The conventional PI controller is one of the most common approaches for speed control in industrial electrical drives in general, because of its simplicity, and the clear relationship existing between its parameters and the system response specifications. It also improves the dynamic response of the system and reduces or eliminates the steady state error and the error sensibility. This is achieved by providing a proportional gain $\left(\mathrm{K}_{\mathrm{p}}\right)$ for the error input term with an integral component correction $\left(\mathrm{K}_{\mathrm{i}}\right)$

$$
u(t)=K_{p} e(t)+K_{i} \int_{0}^{t} e(\tau) d \tau
$$

Where, $u(t)$ is the output of the PI controller and e (t) is the error signal

The conventional PI controller fixed gain may perform well under some operating conditions but not all. The conventional PI controller block model is given in Fig. (5) [3, 6].

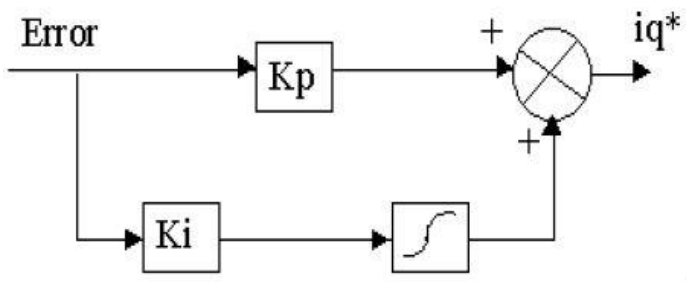

Figure (5) Conventional PI controller

\section{SIMULATION AND RESULTS}

\subsection{Simulation Results for open loop V/F}

The responses of the speed and torque for $\mathrm{V} / \mathrm{F}$ at constant load and different speed conditions have been studied where the ratio of V/F is 4.44(Constant ratio). Fig. (6) Showed Simulink model for VF as following:

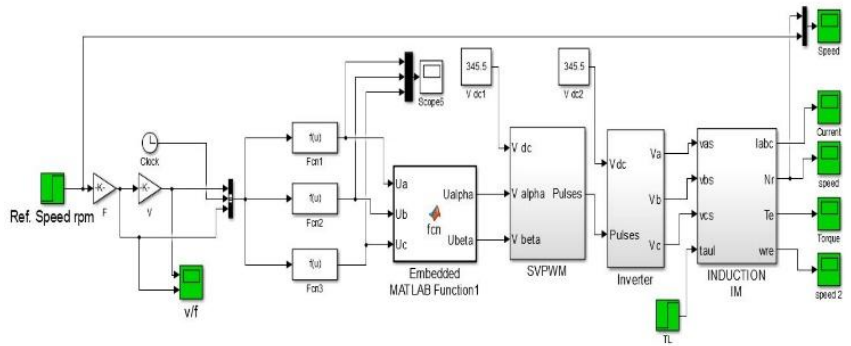

Figure (6) Simulink block of open loop constant V/F speed control

\section{Case 1}

1. At rate load condition $\mathrm{TL}=(0,1)$ at time $(0,0.5 \mathrm{~s}) \mathrm{N}$.m and speed $\mathrm{nr}=1500 \mathrm{rpm}$ at moment of inertai $(\mathrm{J}=0.001 \mathrm{~kg} . \mathrm{m})$, the speed reached to reffrence speed in $0.35 \mathrm{~s}$. Due to the load torque applied, the speed decrease to $1207 \mathrm{rpm}$ at $0.5 \mathrm{~s}$ and no 
overshoot in the speed response, Figures (7), and (8) show the torque and speed response. Fig. (13) shows that the starting torque is high reach to $3 \mathrm{~N} . \mathrm{m}$. then the current equal to 1.6 amp and increamnt after applied load as shown in figure (9)

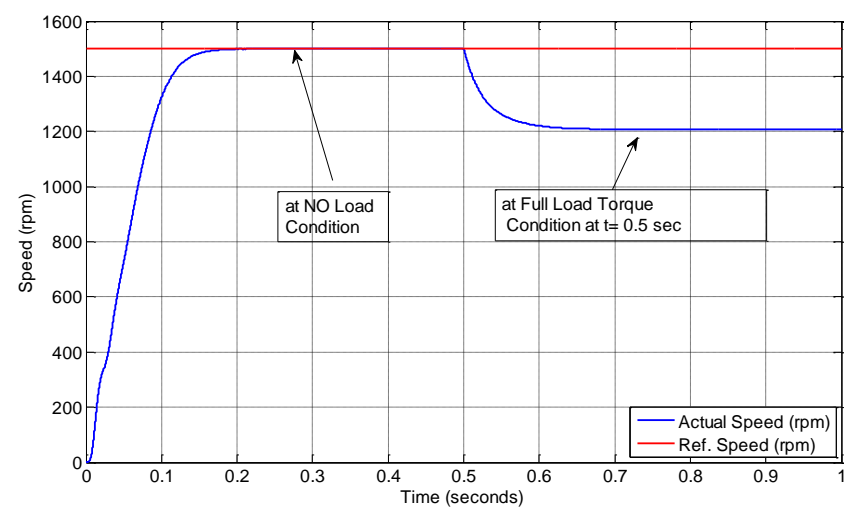

Figure (7) Speed response

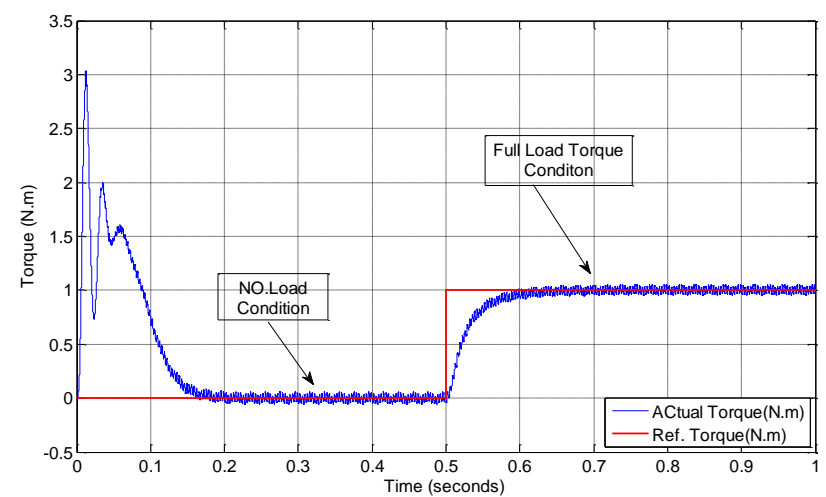

Figure (8): Electromagnetic torque response

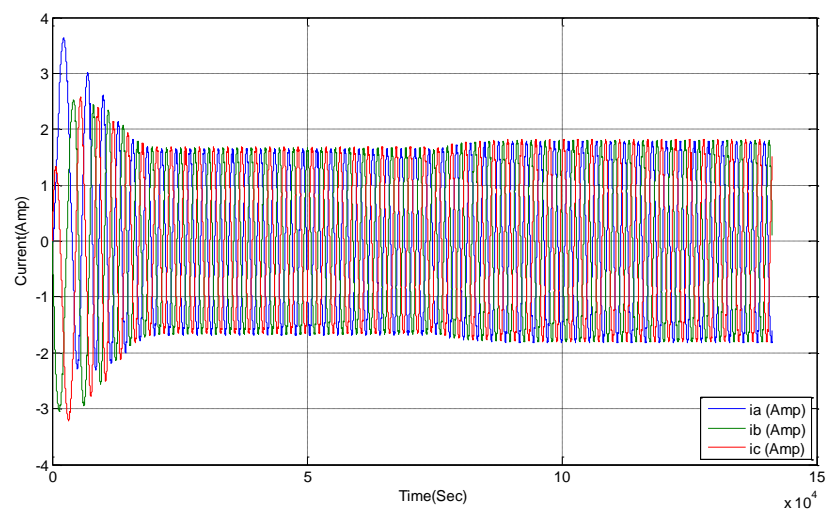

Figure (9) Current response

2. Figures (10) and (11) show the speed and torque responses of IM when the speed is varied from 1000 to $1500 \mathrm{rpm}$ at time $.5 \mathrm{sec}$

A-at No load Condition . In figure (11) show that the starting torque is high reach to $2.5 \mathrm{~N}$.m less than case 1 . when change the speed ,the response take more time to reach for reffrence speed and the torque also change due to speed change or change input volatge and after that back to zero and the current is stay without change as shown in fig.(12)

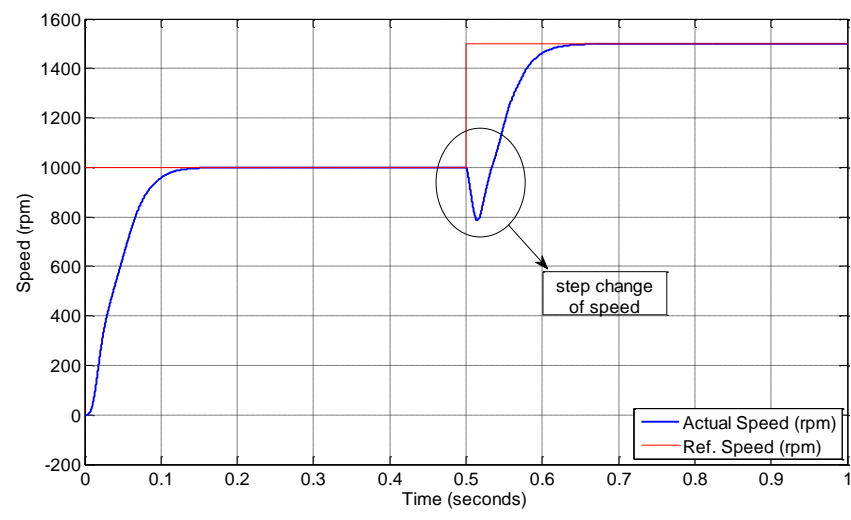

Figure (10): Speed response

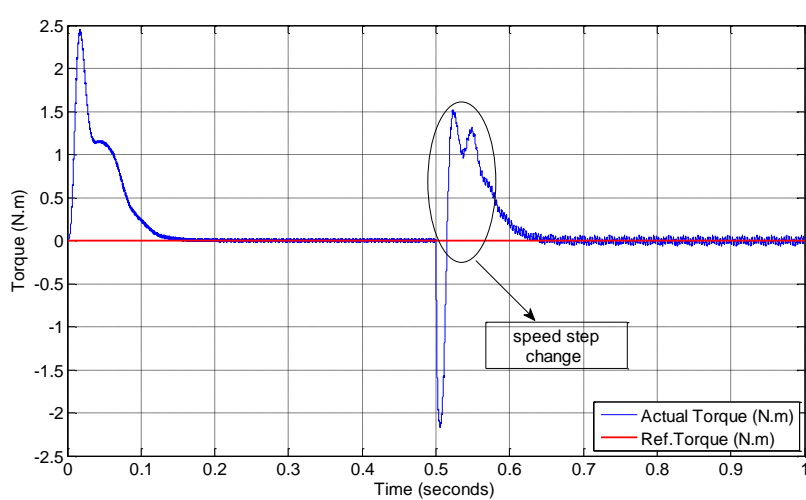

Figure (11): Electromagnetic torque response

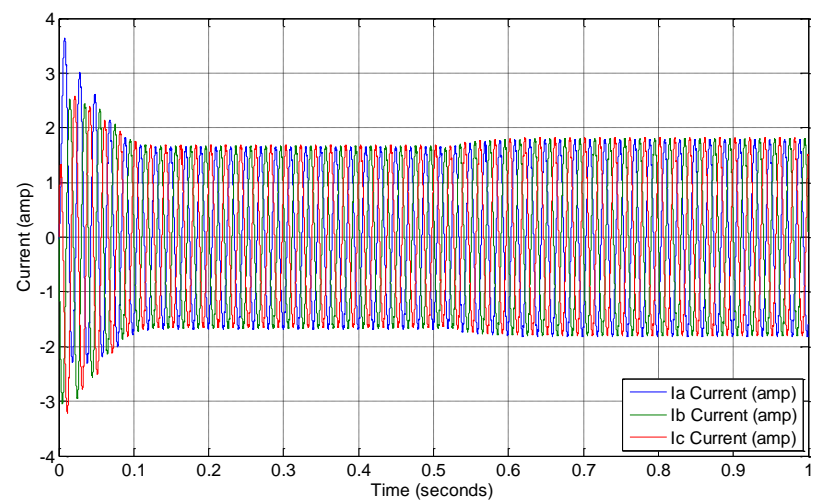

Figure (12) the current response

B-at $T L=1 N$.m, in figure (13) shown the speed response from this figure, it can be seen that the rotor speed cannot reach to the required speed due to the load condition .figure (14) show that the torque has normally dynamic performance under these changes and the current keep without change under varies as shown in fig(15) 


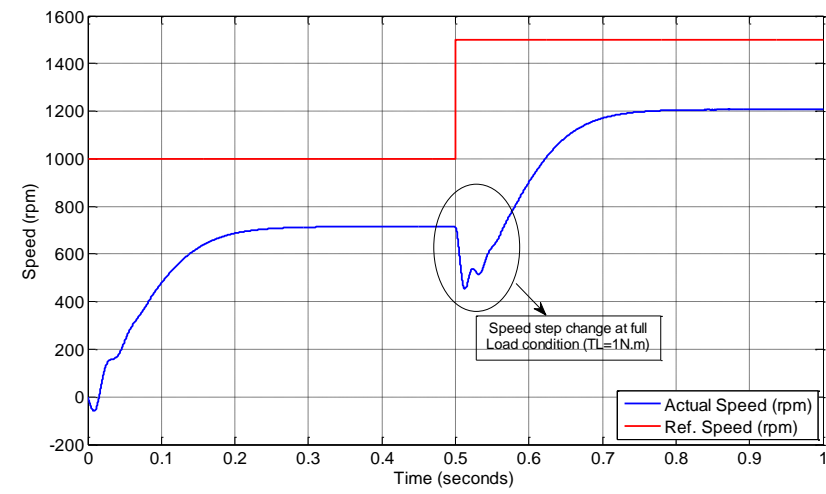

Figure (13) Speed response

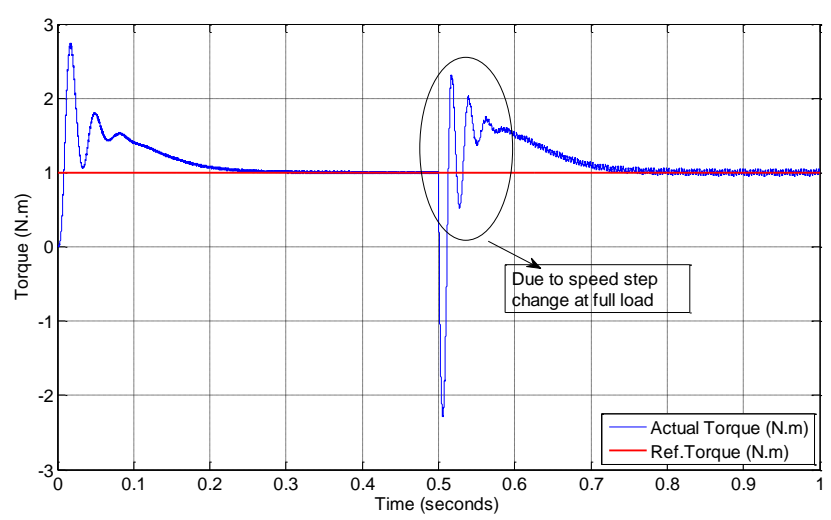

Figure (14) Torque response

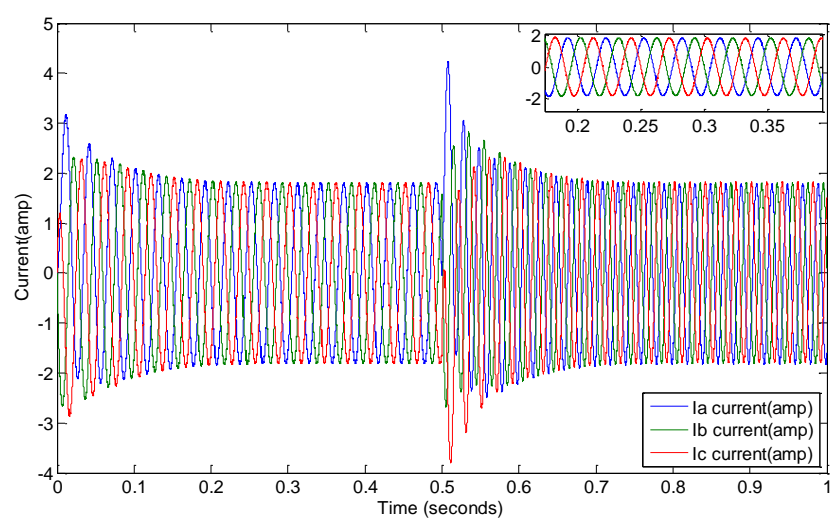

Figure (15) Current response

\subsection{Simulation Results for PI controller}

The simulation circuit of INFOC with PI controller is shown in Fig. (16). A trial and error method is used for tuning the conventional PI controller. The obtained gains are $\mathrm{k}_{\mathrm{p}}$ and $\mathrm{K}_{\mathrm{i}}$.

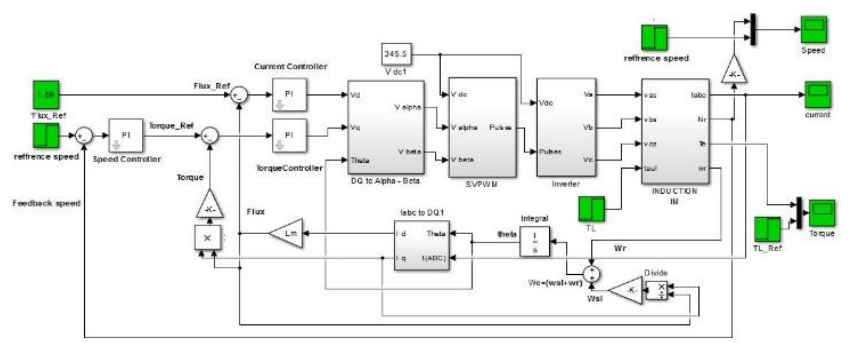

Figure (16) the simulation circuit with PI controller

\section{Case 2:}

1-In this case the speed reference of IM is $1500 \mathrm{rpm}$ and rated load condition is changed in steps from $(0-1)$ N.m at time $0.5 \mathrm{~s}$ and $\mathrm{J}=0.001 \mathrm{Kg} . \mathrm{m}$.in Figures (17), (18) shows that rotor speed follows the reference speed under different torque loads. And starting torque is less than VF this means that the controller is robust and good dynamic response. In figure (19) explain the current response is equal to 5 Amp and no change under different load.

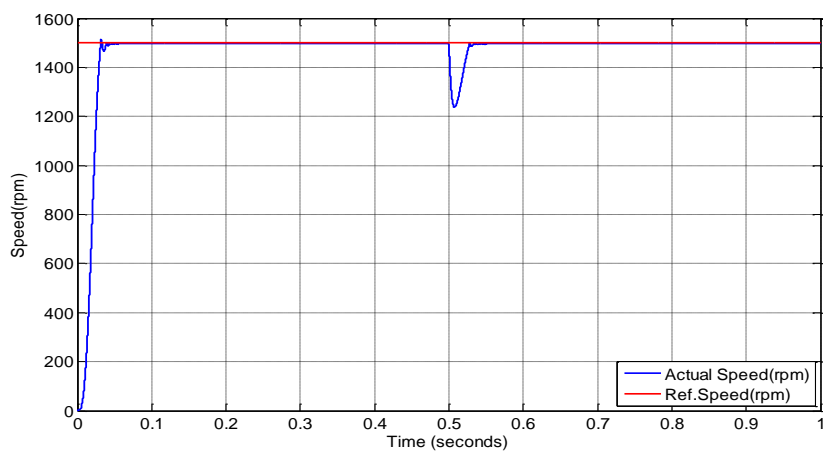

Figure (17): Speed response (1 Nm at $5 \mathrm{sec})$

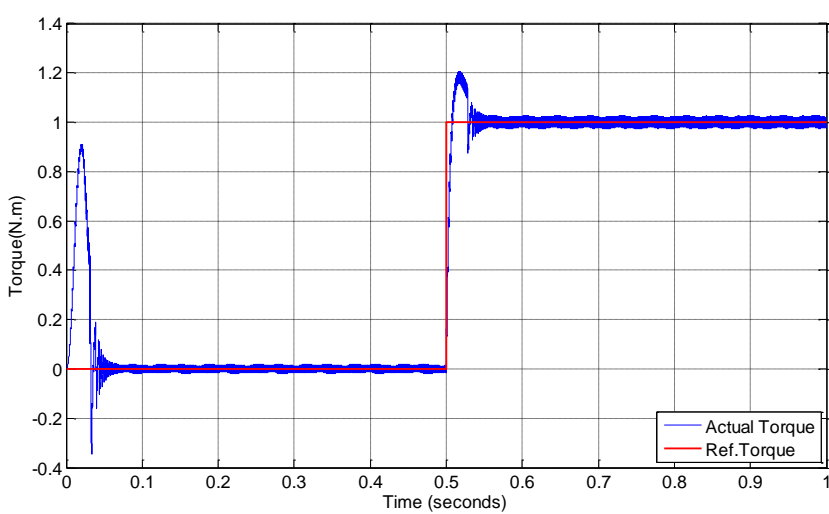

Figure (18) Electromagnetic torque response (1N.m at 5s)

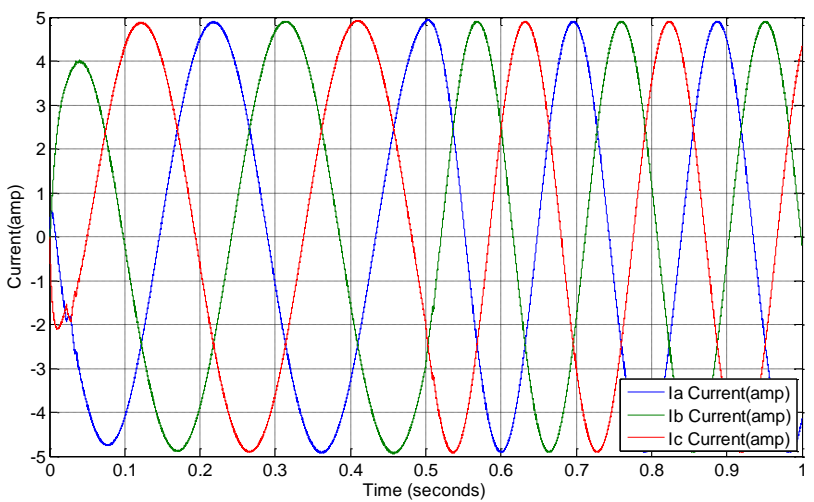

Figure (19) the current response

2- When the speed is change from 1000 up to $1500 \mathrm{rpm}$ at $\mathrm{t}=0.5 \mathrm{sec}$ 
A. No-load torque the current is same as previous case without change. In Figures $(20,21)$ show the responses for the speed, torque

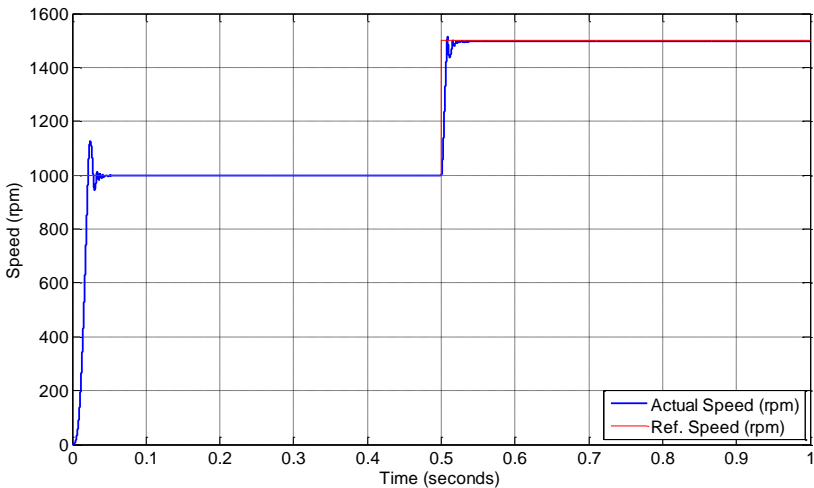

Figure (20) speed response

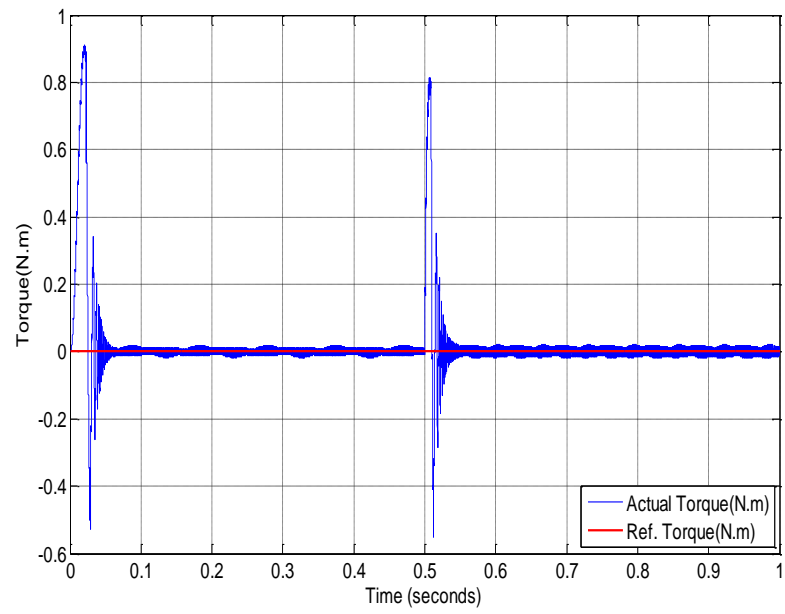

Figure (21) torque response

$\mathrm{B}$-at $\mathrm{TL}=1 \mathrm{~N} . \mathrm{m}$ When the speed is varied from 1000 to 1500 at time $0.5 \mathrm{~s}$.the speed response has small overshot after applied load compared with previous case as shown in figure (22).The torque response is not effect with applied load as figure (23).

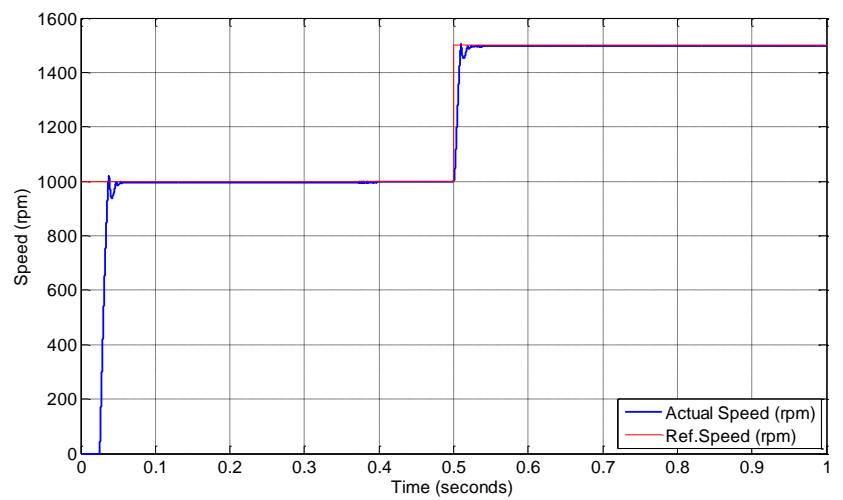

Figure (22) speed response

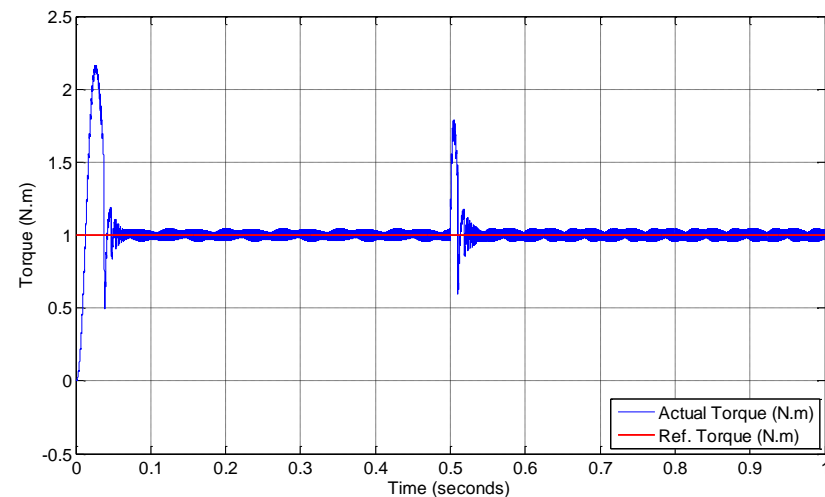

Figure (23) Torque response

\section{CONCLUSION}

It can be concluded that the two control methods scalar control and vector control have advantages and disadvantages. Scalar control is a low cost method, simple and immunity to errors of feedback signals, open loop deals with constant speed applications, many applications in the industry operate with this control technique. The IFOC induction motor drive involves decoupling of the stator current components which produces torque and flux. It can be controlled by using a PI speed control. It improves the dynamic response of the system and reduces the steady state error, the error sensibility, high performance and smooth speed response. The simulation results showed that a good dynamic performance can be obtained from the PI controller compared with the V/F.

\section{APPENDIX}

Table 1. Parameter of IM

\begin{tabular}{|ll|l|}
\hline stator inductance & $(\mathrm{Ls})$ & $0.4 \mathrm{H}$ \\
\hline rotor inductance & $(\mathrm{Lr})$ & $0.4 \mathrm{H}$ \\
\hline Magnetizing & $(\mathrm{LM})$ & $0.3 \mathrm{H}$ \\
\hline stator resistance & $\mathrm{Rs}$ & $20 \mathrm{Ohm}$ \\
\hline rotor resistance & $\mathrm{Rr}$ & $37 \mathrm{Ohm}$ \\
\hline moment of inertia & $\mathrm{J}$ & $0.001 \mathrm{Kg} \cdot \mathrm{m}$ \\
\hline No .of pole & $\mathrm{P}$ & 4 \\
\hline Speed & Ns & $1500 \mathrm{rpm}$ \\
\hline Power & watt & $250 \mathrm{w}$ \\
\hline
\end{tabular}

\section{REFERENCES}

[1] Jay R. Patel and S.R. Vyas "Simulation and Analysis of Constant V/F Induction Motor Drive", International Journal of Engineering and Technical Research (IJETR), Volume -2, Issue 4, pp. 151-156, April 2014.

[2] Majida Khaleel Ahmed," Induction Motor Speed Drive Controller Using Indirect Field oriented and fuzzy logic techniques", University of Technology, Iraq, MSc. thesis, 2007

[3] Wiam Ismael Jabbar," Direct Torque Control of Induction Motor Based on Intelligent Techniques", University of Technology, Iraq, MSc. thesis, 2013 
[4] Kanaan A. Jalal, "Direct Torque Control of Induction Motor Based on Intelligent Systems", PhD Thesis, University of Technology, Iraq, April 2007.

[5] Fadhil Abbas Hassan, "Modeling and Implementation of Space Vector PWM Driver of 3-Phase Induction Motor", University of Technology, Iraq, MSc. thesis, 2008

[6] R. Arulmozhiyal, K.Baskaran, R. Manikandan ", A Fuzzy Based PI Speed Controller For Indirect Vector Controlled Induction Motor Drive "IEEE, 2011 Sona College of Technology, Salem, Tamilnadu 636005, and India.

[7] Pabitra Kumar Behera, Manoj Kumar Behera, Amit Kumar Sahoo," Speed Control of Induction Motor using Scalar Control Technique", International Conference on Emergent Trends in Computing and Communication,(0975 - 8887), ETCC-2014.

[8] Devraj Jee, Nikhar Patel," V/F Control of Induction Motor Drive" , MSc Thesis ,National institute of Technology, May-2013, Odisha, India.

[9] Riya Elizabeth Jose, Maheswaran K.," V/F Speed Control of an Induction Motor Drive Fed by Switched Boost Inverter", International Journal of Advanced Research in Electrical, Electronics and Instrumentation Engineering, Vol. 4, Issue 8, August 2015.
[10] P. M. Menghal, Dr. A. Jaya Laxmi, "Dynamic Modeling, Simulation \& Analysis of Induction Motor Drives", International Conference on Science, Engineering and Management Research, 2014.

[11] Bose. K.B., "Modern Power Electronics and AC Drives", Book, Prentice Hall, 2002.

[12] Burak Ozpineci, Leon M. Tolbert," Simulink Implementation of Induction Machine Model- a Modular Approach", 2003 IEEE, pp 728-734.

[13] M.S.Aspalli., Asha.R, P.V. Hunagund ,"Three Phase Induction Motor Drive Using IGBTs And Constant V/F Method", International Journal of Advanced Research in Electrical, Electronics and Instrumentation Engineering, Vol. 1, Issue 5, November 2012.

[14] G. Kohlrusz, D. Fodor," Comparison of Scalar and Vector Control Strategies of Induction Motors", Hungarian Journal of Industrial Chemistry Veszprém Vol. 39(2) pp. 265-270 (2011).

[15] Anhar Azeez Sagger," Field Oriented Control of an Induction Motor Based on a Single -Phase to Three Phase Indirect Matrix Converter", University of Technology, Iraq, MSc. thesis, June 2016. 